\title{
A Multidisciplinary Approach to Dental Erosion: A Case Report
}

\author{
M. Ustun Guldaga \\ U. Sebnem Buyukkaplan ${ }^{b}$ \\ Zuhal Yetkin Ayc \\ Gunseli Katircid
}

\begin{abstract}
Chemical erosion is the loss of superficial tooth structure by chemical action in the continued presence of demineralizing agents. This can be prominent in patients with oral habits such as constant citrus ingestion (like lemon chewing), chlorinated swimming pool water or gastrointestinal problems that produce repeated exposure of teeth to gastric acids. In this case report, a multidisciplinary approach to restore the severe wear due to dental erosion by proper techniques and materials was presented. (Eur J Dent 2008;2:110-114)
\end{abstract}

Key words: Dental erosion; Citric acid; Non-carious cervical lesion.

\section{INTRODUCTION}

Chemical erosion is the loss of superficial tooth structure by chemical action in the continued presence of demineralizing agents. ${ }^{1}$ This can be prominent in patients with oral habits such as

a Professor and Head, Department of Prosthodontics, Faculty of Dentistry, Suleyman Demirel University, Isparta, Turkey.

b Research Assistant, Department of Prosthodontics, Faculty of Dentistry, Suleyman Demirel University, Isparta, Turkey.

c Assistant Professor, Department of Periodontology, Faculty of Dentistry, Suleyman Demirel University, Isparta, Turkey.

d Research Assistant, Department of Conservative Dentistry, Faculty of Dentistry, Suleyman Demirel University, Isparta, Turkey.

- Corresponding author: U.Sebnem Buyukkaplan Suleyman Demirel Universitesi, Dis Hekimligi Fakultesi, Protetik Dis Tedavisi Anabilim Dali, 32260 Isparta/TURKEY

Phone: +902462113372 Fax: +902462370607

E-mail: sataclamed.sdu.edu.tr constant citrus ingestion (like lemon chewing), continuous exposure to airborne acids, chlorinated swimming pool water or gastrointestinal problems that produce repeated exposure of teeth to gastric acids. ${ }^{1-4}$ Erosion, caused by chemical irritants, can be distinguished from abrasion, caused by mechanical wear, by the location and character of the defects; eroded teeth have a smooth glossy appearance on the facial surface. ${ }^{5}$ In instances of uncertainty, a through history and medical evaluation may elucidate the reason such as related habits and exposure to acids. The $\mathrm{pH}$ value of citric acid (lemon) is reported to be 2.5. Because the critical point at which enamel dissolves is reported to be a $\mathrm{pH}$ of $5.0-5.7$, citric acid can play a significant role in dental erosion..$^{5-7}$ In these patients, the primary cause of loss of tooth structure should be determined to eliminate the etiologic factors before the rehabilitative therapy is undertaken. The aim of this case report was to 
illustrate the rehabilitation of a patient suffering from severe dental erosion because of esthetic and functional concern.

\section{CASE REPORT}

A 63 year-old man was referred to Dental School, Suleyman Demirel University by a general practitioner because of excessive loss of tooth structure, especially at the anterior region. A detailed history was taken to determine the reasons of erosion. On questioning about any habits related to tooth erosion, the patient stated that he had been consuming lemon every day for the past 40 years. He had a habit of chewing one lemon after every meal on a daily basis. On clinical examination, tooth wear was observed at the all dentition which was extreme at the maxillary anterior region. Moreover, cervical erosive lesions in all teeth were noted (Figure 1). The eroded tooth surfaces were glossy and smooth (Figure 2). At the anterior region, the clinical crown length was diminished because of the erosion at the incisal edges (Figures 1 and 2). The sharp edges of eroded areas were disturbing the tongue (Figure 3). The patient had no caries lesions and had a healthy periodontium. Mandibular and maxillary second premolars were missing; however, he had no restorations. The patient did not appear to have

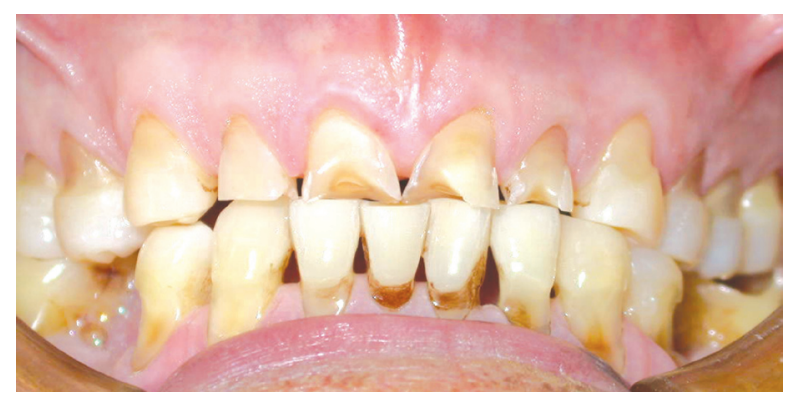

Figure 1. Non-carious cervical lesions.

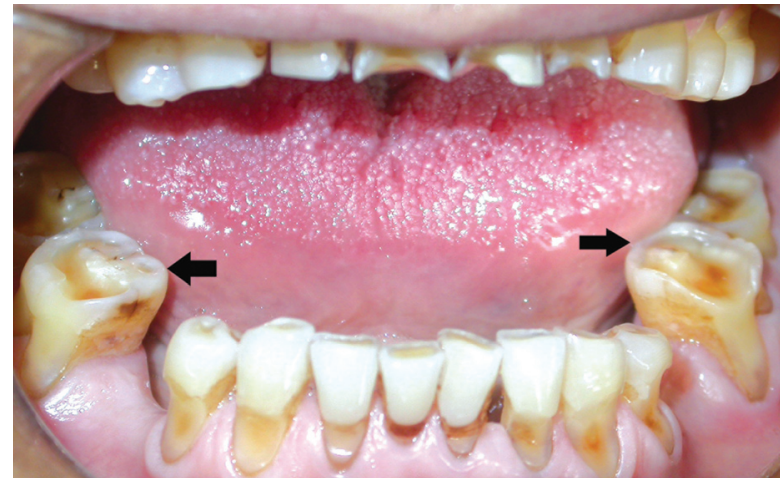

Figure 3. Sharp and eroded occlusal surfaces of mandibular molars.
TMJ dysfunction. All salivary ducts were potent with a free and clear salivary flow.

Medical history revealed that the patient was operated for mitral cuspid deficiency in 1993 and thus he had mitral cuspid prosthesis. The patient was on warfarin, furosemide, simvastatin, spirinolactone medication.

A treatment plan was made and presented to the patient. Because of obvious lack of clinical crown height and need for restoring to functional interarch occlusion, surgical crown lengthening procedure was made. The labial frenulum was removed by frenectomy procedure to obtain optimal gingival esthetics (Figure 4). As the patient had mitral cuspid prosthesis, prophylactic premedication (Amoxicillin, $2 \mathrm{~g} 1$ hours before surgeryl was administered in accordance to the recommendation of his physician. The healing has been completed without any postoperative complications.

The patient's noncarious cervical lesions and occlusal cavities on the upper and lower jaws were restored. Enamel margins were beveled and no cavity preparation was performed in cervical lesions; infected dentin was removed with a round bur and no beveling cavity margins were performed in occlusal cavities. The resin composite (Admira, Voco, Cuxhaven, Germany)

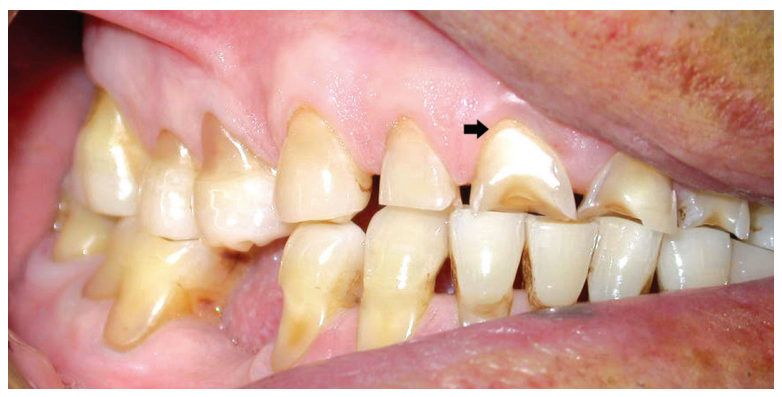

Figure 2. Smooth and glossy appearance of erosion on the facial surface.

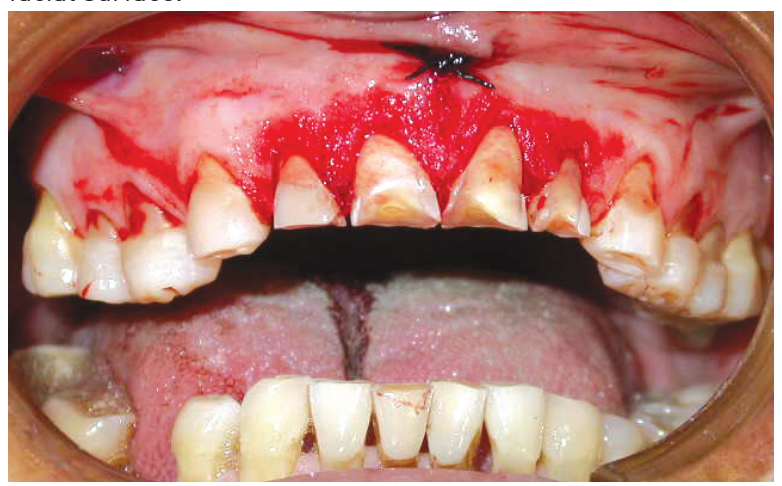

Figure 4. The crown lengthening procedure. 
was placed in increments. Finishing and polishing were performed in standard procedure (Fini, Pentron, Wallingford, USA).

After an adequate period of periodontal healing, the final restorative treatment was commenced. Firstly, occlusal vertical dimension of the patient was evaluated. When the patient closed to maximum intercuspidation with natural teeth, there appeared not to be a decrease in the vertical dimension. Small dots were placed on the tip of the patient's nose and on his chin. To determine resting vertical dimension, the patient was then asked to open and slowly close until his lips touched, at which point a measurement was made. Next, with the teeth in contact, the occlusal vertical dimension was determined. A difference of $3 \mathrm{~mm}$ between the patient's occlusal vertical dimension and resting vertical dimension was measured; therefore occlusal vertical dimension of the patient was not changed. Casts of the dentition and interocclusal records were made. Prosthetic treatment options were discussed with the patient; however the financial sources of the patient were limited the treatment plan. The limitations of the accepted treatment plan was explained to the patient (the esthetics might be better with the lengthening the maxillary teeth and shorten the mandibular anterior teeth to their original shape however as mentioned before the patient insisted on an economical choice). The absence of detectable tooth mobility allowed unconnected single tooth restorations at the maxillary anterior region which would maximize accessibility for oral hygiene and ease of future replacement if required. A threeunit crown and bridge restoration was planned for the restoration of missing molars as the patient could not afford implant-supported prosthesis. For the same reason, the crowns were planned as ceramic fused to metal in place of all-ceramic restorations. The excessive tooth substance loss on the cervical area did not allow shoulder finish line, thus maxillary central and lateral incisors, mandibular fixed partial denture abutments were preparated with chamfer finish line (Dia Burs, Mani Inc. Utsunomiya, Tochigi, Japan). Impressions of the both maxillary and mandibular arches were taken by condensation silicon impression material IOptosil Comfort, Heraus-Kulzer GmbH, Hanau, Germany). Provisional restorations (Structur 2QM, Voco, Cuxhaven, Germanyl were cemented after the tooth preparation procedure. Cementation of the relined acrylic resin provisional restorations was done specifically with a non-eugenol containing temporary cement (Provicol, Voco, Cuxhaven, Germanyl. This was imperative to avoid contamination of the resin based cement to be used for luting definitive crowns. Metal framework (Meganium GT, Megadental GmbH, Budingen, Germany) and porcelain (Noritake, Noritake Dental Supply Co., Ltd., Aichi, Japan) try-in were performed. The porcelain surface of each crown was glazed. The internal surface of crown surfaces was sandblasted (Sandblast Pen, RotaksDent, Istanbul, Turkiye) with 30-40 micron alumina particles (mega-Strahlkorund, Megadental $\mathrm{GmbH}$, Budingen, Germany ) under an air pressure of $4.2-7 \mathrm{~kg} / \mathrm{cm}^{2}$ and then the restoration surfaces were cleaned in an ultrasonic unit (Eurosonic Energy, Euronda, Vicenza, Italyl for 2 minutes. On the maxillary anterior region bonding strength of the single unit restorations was increased using resin based composite cement (Panavia F, Kuraray, Osaka, Japan). The other desirable properties of this material are its exceptional low solubility and high tensile compressive strengths. Lower posterior restorations were cemented with glass ionomer luting cement (Aqua Meron, Voco, Cuxhaven, Germanyl. For the third year after treatment, the patient was followed for routine hygiene and assessment of long-term outcome (Figures 5, 6 and 7).

\section{DISCUSSION}

Dietary factors are the most common etiologic factor implicated in the development of dental erosion. ${ }^{8}$ Fruits, fruit juices and candies with high concentrations of citric acid, carbonated beverages in which citric and phosphoric acids, are the usual extrinsic dietary instigators of dental erosion. . $^{-11}$ In this report, the excessive wear because of lemon chewing restored with multidisciplinary approach was reported. The slowly chewing lemon has an excessive wear effect just as it is in this case..$^{5-7}$

Erosion, abrasion and attrition are becoming more significant as the life expectancy of mankind increases. Such lesions are becoming more frequent, causing several unpleasant symptoms and serious problems in the stomatognatic system. According to some authors as much as $25 \%$ of the pathological destruction of hard dental tissue 
can be attributed to non-carious processes. ${ }^{12}$ The lesions are not only an aesthetic problem but also a functional are with the possibility of loss of masticatory units.

Saliva, with its buffering capacity and its ability to form a protective enamel pellicle, can control dental decalcification. 9.13 The reduction or loss of salivary buffering capacity would contribute to the process of enamel erosion, the occurrence and the progression of dental erosion in this respect has been pointed out by various authors. ${ }^{14,15} \mathrm{An}$ acid challenge results in under saturation of salivary salts (calcium, phosphate) and tooth demineralization with softening of dental enamel occurs. ${ }^{10,16}$ Chemical agents are predominant causative factors in dental erosion and it is generally recognized that tooth brushing and medications are contributing factors. ${ }^{17}$ Dental enamel loss from brushing abrasion will be increased because sufficient time for remineralization will not have passed. ${ }^{16,17}$ This patients susceptibility to dental erosion can be found in the manner of his lemon chewing with his medications which causes xerostomia.

In all studies, which divided the population in to several age groups, it was found that the

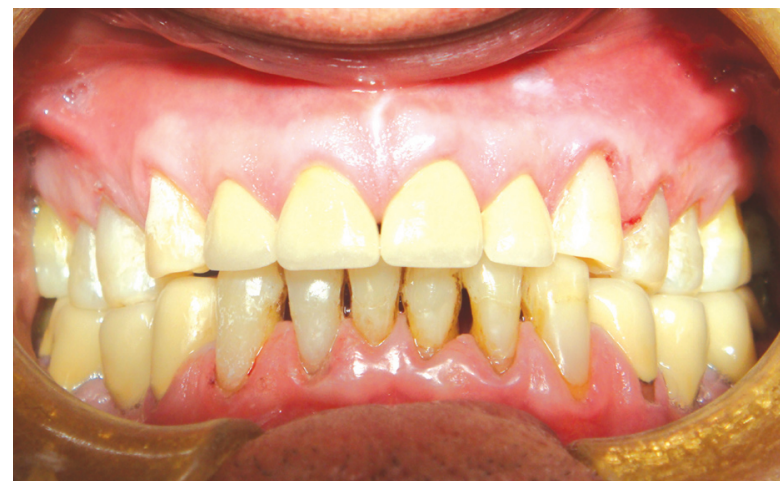

Figure 5. Intraoral photograph after 3 years from the treatment

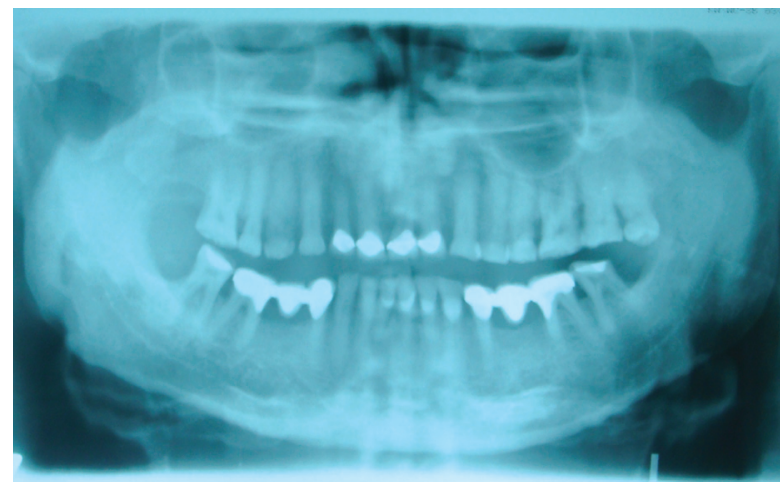

Figure 6. Radiographic appearance after 3 years from the treatment.

April 2008 - Vol.2 number of eroded lesions increased with age. ${ }^{18-22}$ Need of dental care in generalized tooth wear may vary from monitoring and preventive care to increasing occlusal vertical dimension and full mouth restorations. If the causative factor is not eliminated, the wearing is progressive with time. Regular recall for monitoring of candidate patients for generalized tooth wear (such as GERD, use of medications that cause xerostomia, chronic alcoholism, anorexia and bulimia nervosa, industrial work involving exposure to acidic vapors of dust) may help dentists to make preventive measures and an effective dental treatment plan. A nightguard/occlusal splint may be useful to protect the teeth against erosion in GERD and to establish a new vertical dimension in the case of decreased occlusal vertical dimension. In our case, dentoalveolar growth has successfully compensated for the wear rate and the patient preserved with normal resting vertical dimension, freeway space and occlusal vertical dimension. Thus, severe wear due to erosion stopped, restoring the esthetics and function by using proper techniques and materials without an interference to occlusal vertical dimension. In this case, the affected teeth were in an esthetically critical position so that the defects were restored with tooth colored restorations.

\section{CONCLUSIONS}

The patient in our case report presented with generalized dental erosion and he had a history of excess lemon consumption. The use of drugs that cause xerostomia and lowering salivary buffering capacity of his medications were the contributory factors for dental erosion. The damage of dental erosion on dentition was restored with conventional techniques and the patient did not presented any

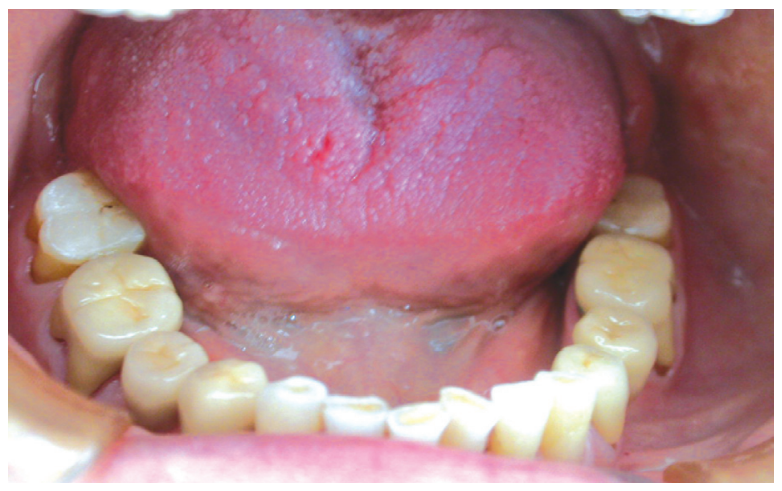

Figure 7. Occlusal appearance of fixed partial dentures.

European Journal of Dentistry 
compliance and symptoms after the 3 years from dental management.

\section{REFERENCES}

1. Grippo JO. Abfractions: a new classification of hard dental tissue lesions of teeth. J Esthet Dent 1991;3:14-19.

2. Järvinen V, Meurman JH, Hyvärinen $H$, Rytömaa I, Murtomaa H. Dental erosion and upper gastrointestinal disorders. Oral Surg Oral Med Oral Pathol 1988;65:298-303.

3. Knewitz JL, Drisko CL. Anorexia nervosa and bulimia: a review. Compendium 1988;9:244-247.

4. Levitch LC, Bader JD, Shugars DA, Heymann HO. Noncarious cervical lesions. J Dent 1994;22:195-207.

5. Poynter ME, Wright PS. Tooth wear and some factors influencing its severity. Restorative Dent 1990;6:8-11.

6. Grippo JO, Simring M. Dental 'erosion' revisited. J Am Dent Assoc 1995;126:619-630.

7. Meurman JH, ten Cate JM. Pathogenesis and modifying factors of dental erosion. Eur J Oral Sci 1996;104:199-206.

8. Imfeld T. Dental erosion. Definition, classification and links. Eur J Oral Sci 1996;104:151-155.

9. Giunta JL. Dental erosion resulting from chewable vitamin C tablets. J Am Dent Assoc 1983;107:253-256.

10. Touyz LZ. The acidity $(\mathrm{pH})$ and buffering capacity of Canadian fruit juice and dental implications. J Can Dent Assoc 1994:60:454-458.

11. West NX, Maxwell A, Hughes JA, Parker DM, Newcombe RG, Addy M. A method to measure clinical erosion: the effect of orange juice consumption on erosion of enamel. J Dent 1998;26:329-335.

12. Marzouk MA, Simounton AL, Gross RD. Operative Dentistry. Modern theory and practice, 1st ed. St Louise- Tokyo, Ishiyahu EuroAmerica Inc. 1985.

13. Meurman JH, Vesterinen M. Wine, alcohol and oral health, with special emphasis on dental erosion. Quintessence Int 2000;31:729-733.

14. Jarvinen V, Rytömaa I, Heinonen OP. Risk factors in dental erosion. J Dent Res 1991;70:942-947.

15. Scheutzel P. Etiology of dental erosion-intrinsic factors. Eur J Oral Sci 1996;104:178-190.

16. Attin T, Koidl U, Buchalla W, Schaller HG, Kielbassa AM, Hellwig E. Correlation of microhardness and wear in differently eroded bovine dental enamel. Arch Oral Biol 1997;42:243-250

17. Hooper S, West NX, Pickles MJ, Joiner A, Newcombe RG, Addy M. Investigation of erosion and abrasion on enamel and dentine: a model in situ using toothpastes of different abrasivity. J Clin Periodontol 2003;30:802-808.

18. Smith BG, Robb ND. The prevalence of toothwear in 1007 dental patients. J Oral Rehabil 1996;23:232-239.
19. Bergström J, Eliasson S. Cervical abrasion in relation to toothbrushing and periodontal health. Scand J Dent Res $1988 ; 96: 405-411$.

20. Sangnes G, Gjermo P. Prevalence of oral soft and hard tissue lesions related to mechanical toothcleansing procedures. Community Dent Oral Epidemiol 1976;4:77-83.

21. Hong FL, Nu ZY, Xie XM. Clinical classification and therapeutic design of dental cervical abrasion. Gerodontics 1988;4:101-103.

22. Sognnaes RF, Wolcott RB, Xhonga FA. Dental erosion. I. Erosion-like patterns occurring in association with other dental conditions. J Am Dent Assoc 1972;84: 571-576. 